\title{
Primary Hemiarthroplasty for Proximal Humeral Fractures in the Elderly: Long-Term Functional Outcome and Social Implications
}

\author{
Michael Dietrich ${ }^{1}$, Christoph Meier ${ }^{2}$, Daniela Zeller ${ }^{1}$, Patrick Grueninger ${ }^{1}$, \\ Roger Berbig ${ }^{3}$, Andreas Platz ${ }^{1}$
}

\begin{abstract}
Background: Primary shoulder hemiarthroplasty is an established treatment modality for complex fractures of the proximal humerus. Long-term functional outcome is often disappointing. However, little is known about social implications particularly in the elderly. Methods: A single-institution case series of consecutive geriatric patients (age $>70$ years) treated with shoulder hemiarthroplasty for complex fractures of the proximal humerus between 1994 and 1997 was analysed. Postoperative morbidity, long-term function, radiological outcome and social implications were evaluated.

Results: Seventy-seven patients fulfilled the study criteria. Median age at the time of operation was 80 years (range 70-93 years). Systemic and local postoperative complications were observed in $8 \%$ including 2 patients (3\%) with revision surgery. Postoperative mortality was $1 \%$. Forty-eight patients $(62 \%)$ were available for follow-up (median 49 months, range $25-80$ months), 22 (29\%) died from causes unrelated to hemiarthroplasty before follow-up and 7 patients (9\%) did not attend follow-up examination. Median Constant-Murley score was 41 points (range 17-77 points). Long-term results concerning pain were satisfying. The Oxford shoulder score ranged from 14 to 40 (median 30). Forty-one patients (85\%) still lived in their original environment and managed their daily life independently despite poor shoulder function. Four patients (8\%) lived in a retirement home and 3 $(6 \%)$ in a nursery home. Eighty percent of our patients
\end{abstract}

were still able to use public transportation, do the daily shopping and wash their whole body by themselves.

Conclusion: Most patients managed their daily life independently despite poor shoulder function.

\section{Key Words}

Hemiarthroplasty · Elderly · Shoulder · Social

implications - Outcome

Eur J Trauma Emerg Surg 2007;33:512-9

DOI 10.1007/s00068-007-6134-5

\section{Introduction}

The complex fracture of the proximal humerus as described by Neer is a severely disabling injury [1]. It is a typical injury of the elderly which becomes more common as the population ages and remains physiologically active. The overall incidence of these fractures is 70/100,000 people a year and raises up to 405/ 100,000 yearly including only the female older than 70 years of age [2].

The severity of this injury is due to the associated vascular compromise. Disruption of the major blood supply leaves the proximal humerus susceptible to avascular necrosis [3]. In addition to vascular compromise, these fractures are often associated with significant comminution, which makes stable open reduction and internal fixation extremely difficult, particularly in old patients with osteoporotic bone.

\footnotetext{
'Department of Surgery, Stadtspital Triemli, Zurich, Switzerland,

${ }^{2}$ Division of Trauma Surgery, University Hospital Zurich, Zurich, Switzerland,

${ }^{3}$ SportClinic Zurich, Zurich, Switzerland.
}

Received: June 30, 2006; revision accepted: October 13, 2006; Published Online: May 19, 2007 
Thus, the management of these fractures is still a challenging problem [4] and hemiarthroplasty is a widely applied technique for these fracture patterns. The reported functional results following primary hemiarthoplasty for fractures of the proximal humerus vary, whereas satisfactory pain relief can usually be achieved [1, 5-8].

Several groups reported patients with relatively pain free shoulders and good functional results after acute shoulder hemiarthroplasty for three- and fourpart fractures of the proximal humerus [1, 5, 8]. However, none of these studies dealt with patients having an average age of over 80 years. Other reports showed disappointing functional results, especially when the procedure was performed in elderly patients [9, 10]. Furthermore, little is known about social implications of impaired shoulder function particularly in the elderly. It was our interest to study postoperative morbidity, long-term glenohumeral function and the social implication of primary hemiarthroplasty for displaced fractures of the proximal humerus in geriatric patients.

\section{Patients and Methods} Inclusion Criteria

The trauma registry was reviewed for fractures of the proximal humerus treated with primary hemiarthroplasty between January 1994 and December 1997. Only patients at an age of 70 years and older were included in our study. Younger patients, preceding osteosynthesis for primary treatment and pathological fractures were all excluded from further evaluation.

\section{Operative Technique and Rehabilitation}

The operative technique was standardized and followed the guidelines by the manufacturer of the prosthesis model used exclusively in this study (Neer II design: Howmedica ${ }^{\circledR}$ Shoulder prosthesis, Shannon Industrial Estate, Co. Clare, Ireland). All patients were operated in beach-chair position under general anesthesia. A deltopectoral approach was performed in each case. The head fragment was removed. The tuberosities were identified, mobilised and stay sutures were placed at the bone-tendon junction. The canal was prepared by hand and drill holes placed in the shaft on either side of the biceps groove. Non-resorbable sutures (3-Ethicon ${ }^{\circledR}$-Mersilene, Polyester, Johnson \& Johnson ${ }^{\circledR}$, UK) were pulled through the holes before cementing. A trial component was inserted to determine proper size of head and shaft and the correct height of the prosthesis. The humeral component was cemented in all cases in $25^{\circ}$ of retro-version. The tuberosities were then reconstructed using heavy, non-absorbable 3-Mersilene sutures. The goal was to attach the tuberosity fragments to the humeral shaft, to each other, and to the fin of the prosthesis. Cancellous bone graft, taken from the removed humeral head, was placed between the tuberosities and the diaphysis to facilitate bone union.

Rehabilitation was started at the first postoperative day with exercises for wrist and elbow. Pendulum exercises of the shoulder were initiated 1 week after the intervention and followed the principles of early passive motion emphasized by Neer [1]. Free range of motion with elevation of more than $90^{\circ}$ and strengthening was started 6 weeks after surgery.

\section{Outcome Measures and Follow-Up}

Clinical radiological records were reviewed for associated injuries, intra- and postoperative complications and duration of stay in hospital. Co-morbidities of these elderly patients were classified analogue the Charlson Index [11]. The initial preoperative radiographs were reviewed by one of the authors (Christoph Meier) and classified by the Neer and AO systems $[12,13]$.

All patients eligible for this study were contacted and called up for follow-up. At follow-up, all patients were examined by a single investigator (Michael Dietrich). Both investigators (Christoph Meier and Michael Dietrich) did not participate in any of the operations.

Assessment of the long-term result included the Constant-Murley shoulder score [14] of the operated and contra lateral side, the Oxford shoulder score [15], and radiographs of the shoulder.

Pain and shoulder function were measured using the well-established Constant-Murley shoulder score. The Oxford shoulder score was completed by the patients unaided at the time of follow-up. This questionnaire contains 12 items, each of which has five categories of response. Each item is scored from 1 to 5, from least to most difficulty or severity, and combined to produce a single score with a range from 12 (least difficulties) to 60 (most difficulties). It has been shown to be consistent and reproducible regarding the patients' perception of shoulder problems $[15,16]$. The test specifically asks for important functions of daily activities (e.g., ability to use knife and fork, to hang up clothes, to use public transportation, etc.).

Radiographic outcome was assessed on a true anteroposterior view of the shoulder in neutral rotation 
and a lateral Y-view. Radiographs were evaluated with specific attention to bone union and adequacy of tuberosity reduction and stem fixation. Loosening of the prosthesis was defined as radio lucent lines greater than $2 \mathrm{~mm}$ or progressive lines at the prosthetic bonecement interface [17]. Proximal migration of the prosthesis was evaluated by measurement of the distance between the summit of the prosthetic head and the line of sclerosis of the acromion on the anteroposterior radiograph in neutral rotation [18]. A correlation between a rotator cuff tear and narrowing of the subacromial space to less than $7 \mathrm{~mm}$, indicating proximal migration of the humerus, is well established in the literature [19-21].

\section{Statistical Analysis}

Results were analysed using the statistical program SPSS $^{\circledR}$ version 11.0 (SPSS, Chicago, IL, USA). Data are presented as median and range.

For continuous data compared between shoulders, statistical analysis was performed using Wilcoxon signed ranks test. Independent groups were compared using Mann-Whitney test. To analyse any correlation between continuous data, Spearman's rank correlation was performed. Spearman rank correlation coefficient was put in brackets. The level of significance was set at $\mathrm{p}<0.05$.

\section{Results}

A total of 77 patients (10 male, 67 female) qualified to enter the study. Median age at the time of surgery was 80 years (range, 70-93 years). Sixty-one patients $(79 \%)$ had at least one pre-existing co-morbidity, 8 $(10 \%)$ patients had three or more (Table 1$)$.

All patients sustained a low energy trauma. Most patients fell over obstacles at home $(n=34,44 \%)$ or by crossing a street $(n=25,32 \%)$. Five patients $(6 \%)$ fell due to a cerebral absence, $6(8 \%)$ fell under the influence of alcohol and $3(4 \%)$ times icy ground was

Table 1. Pre-existing relevant co-morbidities (analogue Charlson index [11]).

\begin{tabular}{lrr}
\hline Co-morbidity & $\mathbf{n}$ & \% \\
\hline Cardiovascular & 53 & 68 \\
COPD & 16 & 21 \\
Diabetes & 21 & 27 \\
Nephropathy & 3 & 4 \\
Carcinoma & 2 & 3 \\
Cerebral & 9 & 12 \\
\hline
\end{tabular}

claimed to be the reason for the incident. Four patients (5\%) broke their arm when getting attacked by a criminal.

The dominant shoulder was affected in $62 \%$. Associated fractures were diagnosed in 15 cases $(20 \%)$ including 4 contra-lateral upper limb fractures (2 radius, 1 humerus, 1 olecranon), 8 lower limb fractures (5 proximal femur fractures, 2 pubic ramus fractures, 1 tibial fracture), 1 fracture of a facial bone as well as 2 patients with fractured ribs.

In 65 patients ( $84 \%$ ) preoperative radiographs were available and suitable for fracture classification. According to the Neer classification, 11 patients (17\%) were treated for a two-part, $26(40 \%)$ for a three-part and $28(43 \%)$ for a four-part fracture. Among these fractures were $8(12 \%)$ fracture-dislocations. Using the AO-classification to categorize these fractures, 7 (11\%) A, 30 (46\%) B and 28 (43\%) C-fractures were observed.

All operations were performed by one of three councillors. They all show a record of more than 10 years of operative experience in shoulder surgery.

Median duration of hospital stay was 17 days (range, 6-98 days). No intraoperative complications occurred. Postoperative morbidity was $8 \%(n=6)$, including $3(4 \%)$ systemic complications (1 cardiac stroke, 1 apoplexy, 1 cardio-pulmonary failure). Local complications $(\mathrm{n}=3,4 \%)$ included 2 patients $(3 \%)$ who had to undergo revision surgery (1 postoperative hematoma, 1 displaced prosthesis) and 1 patient (1\%) with postoperative thrombosis of the subclavian vein. One patient suffering from a known aortic valve stenosis $(1 \%)$ died 7 days after trauma (6 days following shoulder- and hip arthroplasty) as a result of cardiopulmonary failure.

\section{Follow-Up}

Median follow-up was 49 months (range, 25-80 months). Twenty-two patients $(29 \%)$ of the original cohort had already died from causes unrelated to hemiarthroplasty before follow-up. Five patients $(6 \%)$ were unable to participate at the examination due to health problems unrelated to previous shoulder surgery and 2 patients (3\%) could not be located. Thus, physical examination and questioning was performed in a total of 48 patients ( $87 \%$ of all patients alive, $62 \%$ of the initial cohort). At follow-up, median age was 83 years (range, 72-97 years).

\section{Constant-Murley Shoulder Score}

Overall median Constant-Murley shoulder score score was 41 points (range, 17-77 points) on the fractured side and 77 points (range, 33-100 points) on the con- 


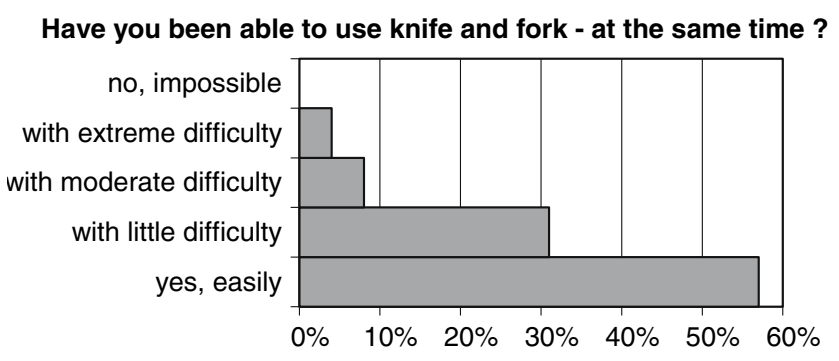

\section{Could you brush/comb your hair with the affected arm ?}

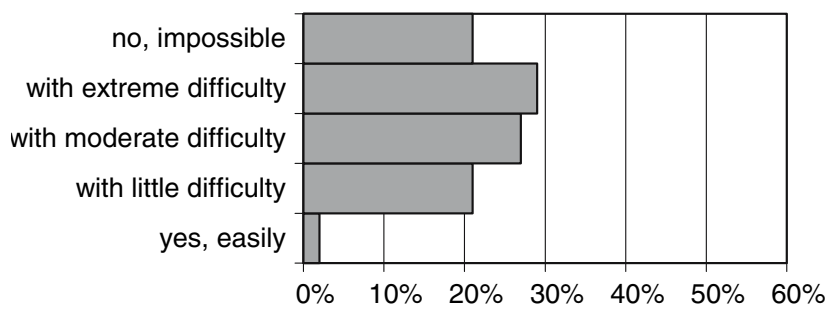

Figure 1. Oxford shoulder score. Detailed results of two different functions regarding an activity positioned in the plane in front of the body and an activity which requires elevation and abduction.

tra-lateral side $(\mathrm{p}<0.01$, correlation coefficient 0.47$)$. Median anterior elevation of the affected shoulder was $70^{\circ}$ (range, $25^{\circ}-115^{\circ}$ ) and lateral abduction was measured $70^{\circ}$ as well $\left(\right.$ range, $\left.25^{\circ}-120^{\circ}\right)$. Only 5 patients $(10 \%)$ were able to lift their arm more than $90^{\circ}$ in anterior elevation or lateral abduction. Power was also markedly reduced. Median isometric power of 6.6 pounds (range, 0-18 pounds) compared with 12 pounds (range, $2-25$ pounds) on the contra-lateral side was observed $(\mathrm{p}<0.01$, correlation coefficient 0.72). Median pain score was 10 points, no patient complained about severe shoulder pain. Sixty-five percent of the patients had no or mild pain (Table 2). Three patients $(6 \%)$ reported to require analgesia (NSAR only) on a daily basis, 6 (13\%) took them occasionally and 39 patients $(81 \%)$ did not require any analgesia at all. Adapted for age and sex, median overall Constant-Murley shoulder score was $62 \%$ (range, 24-100\%). In median, patients reached 52\% of the unaffected shoulder function regarding ConstantMurley shoulder score. Our results clearly showed that

Table 2. Severity of pain (Constant-Murley shoulder score).

\begin{tabular}{lrr}
\hline Pain & $\mathbf{n}$ & $\%$ \\
\hline Severe (0 points) & 0 & 0 \\
Moderate (5 points) & 17 & 35 \\
Mild (10 points) & 19 & 40 \\
None (15 points) & 12 & 5 \\
\hline
\end{tabular}
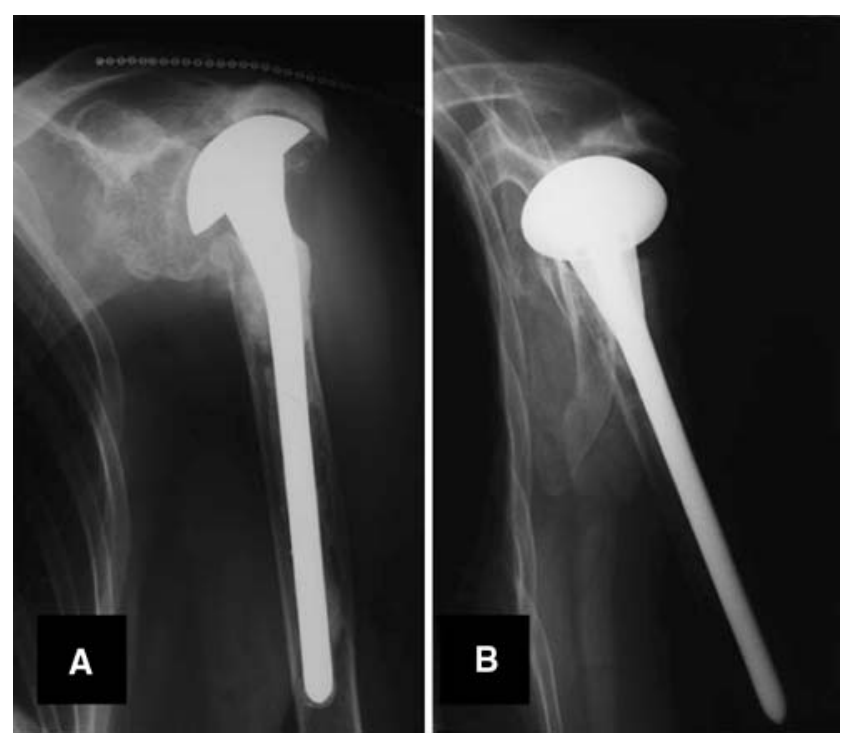

Figure 2. Example of follow-up radiographs (a: anteroposterior view, b: lateral Y-view) demonstrating marked narrowing of subacromial space and absorbed tuberosities.

patients with the best functional results had the least pain and vice versa $(\mathrm{p}<0.01)$.

No significant correlation between fracture classification and outcome regarding function or pain was seen.

\section{Oxford Shoulder Score}

Median Oxford shoulder score was 30 (range, 14-40, Figure 1). Despite reduced range of motion of the affected shoulder, there was no limitation in function of the hand. All daily duties positioned in the plane in front of their body could be managed properly (e.g., working with fork and knife). In contrast, the most common limitations in case of fair or poor functional results were hair combing or hanging up clothes (Table 3).

\section{Social Implications}

Forty-one patients $(85 \%)$ were still able to live by themselves in their original environment, some of them supported by occasional aid to pursue their daily activities. Four patients $(8 \%)$ lived in a retirement home, $3(6 \%)$ in a nursery home. Eighty percent of the patients were able to use public transportation, do the daily shopping, eat with utensil as well as they were able to wash their whole body by themselves.

\section{Radiographic Results}

Forty patients $(52 \%)$ of those 48 who were physically examined were available also for radiological followup. Eight patients had to be visited outside of the 
Table 3. Oxford shoulder score (12-item shoulder questionnaire).

\begin{tabular}{llrlr}
\hline $\begin{array}{l}\text { Scoring category } \\
\text { (compromise) }\end{array}$ & \multicolumn{2}{l}{$\begin{array}{l}\text { Normal to } \\
\text { moderate }\end{array}$} & \multicolumn{2}{l}{$\begin{array}{l}\text { Severe or } \\
\text { impossible }\end{array}$} \\
& $\begin{array}{l}\text { 1-3 points } \\
\text { n }\end{array}$ & 4-5 & \multicolumn{2}{c}{ points } \\
n & \% \\
\hline Worst pain from shoulder & 44 & 92 & 4 & 8 \\
Doing household, shopping alone & 40 & 83 & 8 & 17 \\
Trouble with dressing & 47 & 98 & 1 & 2 \\
Carrying a tray of food & 41 & 85 & 7 & 15 \\
Using a knife and fork & 46 & 96 & 2 & 4 \\
Combing hair & 24 & 50 & 24 & 50 \\
Trouble with transport & 44 & 92 & 4 & 8 \\
Usual level of shoulder pain & 43 & 90 & 5 & 10 \\
Hanging clothes in wardrobe & 25 & 52 & 23 & 48 \\
Work interference due to pain & 44 & 92 & 4 & 8 \\
Washing under both arms & 48 & 100 & 0 & 0 \\
Pain in bed at night & 40 & 83 & 8 & 17 \\
\hline
\end{tabular}

hospital and therefore did not get any X-ray. In 7 individuals (18\%) ectopic bone formation was seen. No signs for implant loosening were evident on follow-up radiographs. Union of both the tuberosities and parts of them in correct position was observed in 21 patients $(52 \%)$. Nineteen patients $(48 \%)$ presented with at least one absorbed, ununited or totally malpositioned tuberosity (Figure 2). In 7 cases (18\%), no tuberosities could be identified on the radiographs indicating complete resorption.

Comparing the group with parts of both tuberosities identified in a correct position $(\mathrm{n}=21,52 \%)$ with the group with at least one tuberosity completely resorbed $(\mathrm{n}=19,48 \%)$, a significant statistical difference was found regarding overall median Constant score [46 points (range, $28-77$ points) vs. 31 points (range, $17-58$ points), $\mathrm{p}<0.01$ ]. They also claimed less pain [median Constant-Murley shoulder score for pain, 10 points (range, 5-15 points) vs. 8 points (range, 5-15 points), $\mathrm{p}<0.01$ ]. Better isometric power was as well observed in those patients [median ConstantMurley shoulder score for power, 8 pounds (range, $2-18$ pounds) vs. 5 pounds (range, $0-10$ pounds) $\mathrm{p}<0.01$ ]. The sole radiological absence of the greater tuberosity was clearly associated with impaired shoulder function [Constant-Murley score 45 (range, 21-77) vs. 30.5 (range, 17-55), $\mathrm{p}=0.01]$.

Proximal migration of the prosthesis as demonstrated by an acromiohumeral distance less than $7 \mathrm{~mm}$ on the anteroposterior radiograph was present in 22 patients $(55 \%)$. These patients showed less isometric power [median Constant score for power, 5.5 pounds (range, $2-14$ pounds) vs. 7 pounds (range,
$0-18$ pounds), $\mathrm{p}=0.03$ ]. They had a smaller range of motion [median Constant-Murley shoulder score for function, 12 points (range, 4-24 points) vs. 8 points (range, 2-28 points), $\mathrm{p}=0.03$ ], but there was no difference in pain perception in those patients [median Constant-Murley shoulder score for pain, 10 points (range, 5-15 points) vs. 10 points (range, $5-15$ points)].

All 7 patients (18\%) with both tuberosities absorbed on the radiographs showed a narrowing of the subacromial space to less than $5 \mathrm{~mm}$. In radiographies that showed an absorbed greater tuberosity $(\mathrm{n}=12$, $30 \%)$ subacromial space was significantly narrower [median, $3.5 \mathrm{~mm}$ (range, $0-8 \mathrm{~mm}$ ) vs. median, $7.5 \mathrm{~mm}$ (range, $2-18 \mathrm{~mm}$ ), $\mathrm{p}=0.02$ ].

\section{Discussion}

In geriatric patients requirements for successful surgical treatment of proximal humeral fractures include "one-time surgery", low postoperative morbidity even in high-risk patients, acceptable function and good pain relief. In many individuals, pain can be a greater problem than the restriction in range of motion, especially in elderly patients with relatively reduced demands for physical performance [9]. Primary shoulder hemiarthroplasty fulfilled all these requirements in our series. It was safe and associated with low postoperative morbidity in respect to age and co-morbidities of our geriatric patients. By replacing the humeral head, common problems of head-preserving therapies such as ischemic necrosis of the humeral head, implant loosening or secondary fracture displacement are avoided [22]. Furthermore, secondary implantation, as salvage procedure following failed osteosynthesis or non-operative treatment may lead to increased postoperative morbidity compared with primary hemiarthroplasty [5, 23, 24].

The late finding of superior migration of the prosthesis and its adverse effect on shoulder function has been described previously. Accurate tuberosity reconstruction was found to have a great impact on functional outcome $[17,18,25,26]$. Boileau et al. [18] reported final tuberosity malposition in $50 \%$ of their patients, resulting in superior migration of the prosthesis, stiffness, weakness and persistent pain. Among other factors, age and sex (women over 75 years of age) significantly correlated with failure of tuberosity osteosynthesis leading to poor outcomes. In the present investigation, mainly patients incorporating these "risk factors" for poor outcome (median age 80 years, $87 \%$ female) were studied. Analysis of our results showed that cranial migration of the prosthesis was 
Table 4. Comparison of the current study with other investigations regarding functional outcome of hemiarthroplasty for fractures of the proximal humerus. (FU: Follow-up; CS: Constant-Murley shoulder score; NA: not available).

\begin{tabular}{|c|c|c|c|c|c|c|c|}
\hline Author & Year & Prosthesis & $\mathbf{n}$ & Age & FU (mts) & CS & Elevation $\left({ }^{\circ}\right)$ \\
\hline Tanner and Cofield [5] & 1982 & Neer-Type & 49 & 69 & 38 & NA & NA \\
\hline Hawkins and Switlyk [28] & 1991 & Neer-II, 3M ${ }^{\circledR}$, St Paul & 29 & 64 & 48 & NA & 72 \\
\hline Moeckel et al. [6] & 1991 & Modular component & 22 & 70 & 36 & NA & 119 \\
\hline Wretenberg and Eklund [9] & 1997 & Neer-3M ${ }^{\circledR}$, Rotherham & 18 & 82 & 42 & NA & 55 \\
\hline Hoellen et al. [22] & 1997 & Global shoulder-Prot ${ }^{\circledR}$ & 30 & 74 & 12 & 48 & NA \\
\hline Dimakopoulos et al. [29] & 1997 & Biomodular, $3 \mathrm{M}^{\circledR}$ & 38 & 56 & 37 & NA & 130 \\
\hline Ballmer and Hertel [30] & 1998 & NA & 34 & 70 & 42 & NA & 101 \\
\hline Zyto et al. [27] & 1998 & Neer-II, $3 M^{\circledR}$ & 27 & 71 & 39 & 46 & 70 \\
\hline Boss and Hintermann [31] & 1999 & Neer-II modular & 20 & 77 & 32 & 52 & 99 \\
\hline Prakash et al. [32] & 2002 & Neer-II, 3M ${ }^{\circledR}$, DePuy ${ }^{\circledR}$ & 22 & 69 & 33 & NA & 93 \\
\hline Boileau et al. [18] & 2002 & Aequalis ${ }^{\circledR}$ & 66 & 66 & 27 & 56 & 101 \\
\hline Becker et al. [33] & 2002 & DePuy ${ }^{\circledR}$ & 27 & 67 & 48 & 45 & 89 \\
\hline Schittko et al. [34] & 2003 & OrTra ${ }^{\circledR}$-Prothese & 43 & NA & NA & 54 & 54 \\
\hline Robinson et al. [26] & 2003 & $3 \mathrm{M}^{\circledR}$, Osteonics $^{\circledR}$ & 138 & 68 & 76 & 64 & NA \\
\hline Kralinger et al. [25] & 2004 & DePuy ${ }^{\circledR}$ and others & 167 & 70 & 29 & 55 & NA \\
\hline Schmal et al. [35] & 2004 & EPOCA ${ }^{\circledR}$ C.O.S. & 20 & 70 & 14 & 52 & NA \\
\hline Current study & 2006 & Neer-II, Howmedica ${ }^{\circledR}$ & 77 & 83 & 49 & 41 & 70 \\
\hline
\end{tabular}

associated with poor function and less isometric power. However, we did not find an association of prosthesis migration with pain. In contrast, tuberosity complications, such as resorption, malreduction or migration, significantly correlated with worse range of motion, reduced power and more pain. Furthermore, no correlation between fracture classification and outcome regarding function or pain was observed in our series. This is in accordance with findings of other investigations [6, 27] (Table 4).

Functional results after shoulder hemiarthroplasty for fractures of the proximal humerus have generally been disappointing with a marked impairment of the active range of motion in most investigations found in the literature (Table 3). However, these studies are difficult to compare as they differ in patient demographics and outcome measures. As a matter of fact, a statistical correlation between outcome and age was recently demonstrated $[6,18,26]$. With a median age of 80 years at surgery and 83 years at follow-up, the present investigation contains one of the oldest patient cohorts with one of the longest follow-up time periods.

The well-established Constant-Murley shoulder score contains both subjective and objective elements [14]. Objective measurements of the active range of motion and power are allocated 65 points together, out of a total of 100. Subjective assessment of pain and activities of daily living are allocated 35 points. In the elderly, the range of motion and power may be of inferior relevance compared with the perception of pain and the ability to manage the daily life independently. Whereas most reports found in the literature investigated shoulder function after hemiarthroplasty [22, 23, 25-27, 29, 30, 33], social implications following this procedure are poorly studied. A search of the literature revealed only one study, which addressed these issues in a similar patient group and follow-up compared with our investigation [9]. However, its small number of patients limited this study and social implications of the impaired shoulder function were mentioned but not addressed in detail. In the herein presented investigation the clinical evaluation was focused on the patients' abilities to master their daily life. The Oxford shoulder score proved to be a very suitable tool for assessing the patient's perception of shoulder problems and their impact on daily routine $[15,16]$. It contains only 12 simple questions regarding pain and common activities, each coming with 5 possible answers to choose from. In an evaluation of 155 different musculoskeletal outcomes measures and instruments, the Oxford shoulder score was validated against the Constant-Murley score, the SF-36 and the Health Assessment Questionnaire [36]. Its overall quality as an outcome instrument (methodological evaluation and clinical utility) scored 9 points out of 10 . In our investigation, the Oxford shoulder score proved to be easy to complete unaided even by elderly patients.

Our results demonstrate, that even with marked impairment of shoulder function, most geriatric patients could preserve fundamental activities of daily 
living, which enabled them to pursue a self-contained life in their original environment. Furthermore, hemiarthroplasty provided satisfactory pain relief with the majority of the patients having none to moderate shoulder pain and only $17 \%$ suffering from shoulder pain in bed at night at long-term follow-up.

With modern techniques and implants, such as locked compression plates or nail systems which provide angular stability, osteosynthesis instead of hemiarthroplasty, has gained increasing popularity, even for pluri-fragmental fractures in osteoporotic bone. Whether this recent development changes the indication for shoulder hemiarthroplasty in geriatric patients has not been conclusively answered in the literature, yet. Further studies, comparing not only functional results, but long-term pain relief, social implications and costs are required to evaluate the roles and indications for shoulder hemiarthroplasty and head-preserving techniques in modern fracture treatment.

\section{Acknowledgment}

The authors would like to thank Professor B. Seifert, Department of Biostatistics, ISPM, University of Zurich, for providing assistance with all the statistical issues of this manuscript.

\section{References}

1. Neer CS. Displaced proximal humeral fractures. Part II. Treatment of three-part, four-part displacement. J Bone Joint Surg (Am) 1970;52-A:1090-103.

2. Lind $\mathrm{T}$, Kroner $\mathrm{K}$, Jensen J. The epidemiology of fractures of the proximal humerus. Arch Orthop Trauma Surg 1989;108:285-7.

3. Neumann K, Muhr G, Breitfuss H. Primary humerus head replacement in dislocated proximal humeral fracture. Indications, technique, results. Orthopade 1992;21:140-7.

4. Mills $\mathrm{HJ}$, Horne G. Fractures of the proximal humerus in adults. J Trauma 1985;25:801-5.

5. Tanner MW, Cofield RH. Prosthetic arthroplasty for fractures and fracture-dislocations of the proximal humerus. Clin Orthop 1983;179:116-28.

6. Moeckel BH, Sculco TP, Alexiades MM, Dossick PH, Inglis AE, Ranawat CS. Modular hemiarthroplasty for fractures of the proximal part of the humerus. J Bone Joint Surg (Am) 1992;74A:884-9.

7. Goldman RT, Koval KJ, Cuomo F, Gallagher MA, Zuckerman JD. Functional outcome after humeral head replacement for acute three- and four-part proximal humeral fractures. J Shoulder Elbow Surg 1995;4:81-6.

8. Compito CA, Self EB, Bigliani LU. Arthroplasty and acute shoulder trauma. Reasons for success and failure. Clin Orthop Relat Res 1994;307:27-36.

9. Wretenberg $P$, Eklund A. Acute hemiarthroplasty afrer proximal humerus fracture in old patients. A retrospective evaluation of 18 patients followed for 2-7 years. Acta Orthop Scand 1997;68:121-3.
10. Movin T, Sjoden GO, Ahrengart L. Poor function after shoulder replacement in fracture patients. A retrospective evaluation of 29 patients followed for 2-12 years. Acta Orthop Scand 1998;69:392-6.

11. Charlson ME, Pompei P, Ales KL, Mac Kenzie CR. A new method of classification prognostic comorbidity in longitudinal studies: development and validation. J Chron Dis 1987;40:373-83.

12. Neer CS. Displaced proximal humeral fractures: part I classification and evaluation. J Bone Joint Surg (Am) 1970;52:1077-89.

13. Jakob RP, Kristiansen T, Mayo K, Ganz R, Muller ME. Classification and Aspects of Fractures of the Proximal Humeri. In: Bateman JE, Welsh RP (eds). Surgery of the Shoulder. St Louis, Decker 1984, pp 330-43.

14. Constant $\mathrm{CR}$, Murley AH. A clinical method of functional assessment of the shoulder. Clin Orthop Relat Res 1987;214:160-4.

15. Dawson J, Fitzpatrick R, Carr A. Questionnaire on the perceptions of patients about shoulder surgery. J Bone Joint Surg (Br) 1996;78-B:593-600.

16. Dawson J, Hill G, Fitzpatrick R, Carr A. The benefits of using patient-based methods of assessment. J Bone Joint Surg Surg (Br) 2001;83-B:877-82.

17. Mighell MA, Kolm GP, Collinge CA, Frankle MA. Outcomes of hemiarthroplasty for fractures of the proximal humerus. J Shoulder Elbow Surg 2003;12:569-77.

18. Boileau P, Krishnan SG, Tinsi L, Walch G, Coste JS, Mole D. Tuberosity malposition and migration: reasons for poor outcomes after hemiarthoplasty for displaced fractures of the proximal humerus. J Shoulder Elbow Surg 2002;11:401-12.

19. Cotton RE, Rideout DF. Tears of the humeral rotator cuff. A radiological and pathological necropsy survey. J Bone Joint Surg 1964;46:314-28.

20. Golding FC. The shoulder - the forgotten joint. Br J Radiol 1962;35:149-58.

21. Azzoni R, Cabitza P. Sonographic versus radiographic measurement of the subacromial space width. Chir Organi Mov 2004;89:143-50.

22. Hoellen IP, Bauer G, Holbein O. Prosthetic humeral head replacement in dislocated humerus multi-fragment fracture in the elderly - an alternative to minimal osteosynthesis? Zentralb Chir 1997;122:994-1001.

23. Boileau P, Trojani C, Walch G, Krishnan SG, Romeo A, Sinnerton R. Shoulder arthroplasty for the treatment of the sequelae of fractures of the proximal humerus. J Shoulder Elbow Surg 2001;10:299-308.

24. Antuna SA, Sperling JW, Sanchez-Sotelo J, Cofield RH. Shoulder hemiarthroplasty for proximal humeral malunions: long-term results. J Shoulder Elbow Surg 2002;11:122-9.

25. Kralinger F, Schwaiger R, Wambacher M, Farrell E, Menth-Chiari E, Hubner C, Resch H. Outcome after primary hemiarthroplasty for fracture of the head of the humerus. A retrospective multicentre study of 167 patients. Bone Joint Surg 2004;86-B:217-9.

26. Robinson CM, Page RS, Hill RMF, Sanders LD, Court-Brown CM, Wakefield AE. Primary hemiarthroplasty for treatment of proximal humeral fractures. J Bone Joint Surg 2003;85-A:1215-23.

27. Zyto K, Wallace WA, Frostick SP, Preston BJ. Outcome after hemiarthoplasty for three- and four-part fractures of the proximal humerus. J Shoulder Elbow Surg 1998;7:85-9.

28. Hawkins RJ, Switlyk P. Acute prosthetic replacement for severe fractures of the proximal humerus. Clin Orthop Relat Res 1991;289:156-6o. 
29. Dimakopoulos P, Potamitis N, Lambiris E. Hemiarthoplasty in the treatment of comminuted intraarticular fractures of the proximal humerus. Clin Orthop Relat Res 1997;341:7-11.

30. Ballmer FT, Hertel R. Indications and results of shoulder prosthetics in complex proximal humerus fractures. Ther Umsch 1998;55:197-202.

31. Boss AP, Hintermann B. Primary endoprosthesis in comminuted humeral head fractures in patients over 60 years of age. Int Orthop 1999;23:172-4.

32. Prakash U, McGurty DW, Dent JA. Hemiarthroplasty for severe fractures of the proximal humerus. J Shoulder Elbow Surg 2002;11:428-30.

33. Becker R, Pap G, Machner A, Neumann WH. Strength and motion after hemiarthroplasty in displaced four-fragment fracture of the proximal humerus: 27 patients followed for 1-6 years. Acta Orhop Scand 2002;73:44-9.

34. Schittko A, Braun W, Ruter A. Experiences with the OrTraprosthesis in primary prosthetic replacement of fractures of the humeral head - indication, technique and results. Zentralbl Chir 2003;128:12-6.
35. Schmal H, Klemt C, Sudkamp NP. Evaluation of shoulder arthroplasty in treatment of four-fragment fractures of the proximal humerus. Unfallchirurg 2004;107:575-82.

36. Suk M, Hanson BP, Norvell DC, Helfet DL. Shoulder, Oxford Shoulder Score. In: Suk M, Hanson BP, Norvell DC, Helfet DL (eds). AO handbook. Musculoskeletal outcomes measures and instruments. Davos, AO Publishing 2005, pp 76-9.

\section{Address for Correspondence}

Michael Dietrich, MD

Department of Surgery

Stadtspital Triemli

Birmensdorferstrasse 497

8063 Zurich

Switzerland

Phone (+41/44) 466-1079, Fax -2601

e-mail: michael.dietrich@triemli.stzh.ch 